\title{
Allylic alcohols and amines by carbenoid eliminative cross-coupling using epoxides or aziridines
}

\author{
Matthew J. Fleming and David M. Hodgson*
}

\author{
Letter \\ Address: \\ Department of Chemistry, Chemistry Research Laboratory, University \\ of Oxford, Mansfield Road, Oxford OX1 3TA, United Kingdom \\ Email: \\ David M. Hodgson* - david.hodgson@chem.ox.ac.uk \\ * Corresponding author \\ Keywords: \\ alkenes; aziridines; epoxides; lithiation; synthetic methods
}

Beilstein J. Org. Chem. 2021, 17, 2385-2389.

https://doi.org/10.3762/bjoc.17.155

Received: 27 July 2021

Accepted: 31 August 2021

Published: 10 September 2021

Associate Editor: D. Spring

(C) 2021 Fleming and Hodgson; licensee Beilstein-Institut. License and terms: see end of document.

\begin{abstract}
$\alpha$-Lithiated terminal epoxides and $N$-(tert-butylsulfonyl)aziridines undergo eliminative cross-coupling with $\alpha$-lithio ethers, to give convergent access to allylic alcohols and allylic amines, respectively. The process can be considered as proceeding by selective strain-relieving attack (ring-opening) of the lithiated three-membered heterocycle by the lithio ether and then selective $\beta$-elimination of lithium alkoxide.
\end{abstract}

\section{Introduction}

Methods for the convergent generation of alkenes can be of significant utility in organic synthesis [1]. A relatively underexamined approach is through the interaction of two carbenoids [2]. Dimerisation of carbenoids may compete with a desired carbenoid transformation although its value has been demonstrated in, for example, our studies on lithium 2,2,6,6-tetramethylpiperidide (1, LTMP)-induced syntheses of 2-ene-1,4diols and 2-ene-1,4-diamines from terminal epoxides [3] and aziridines [4,5], respectively (Scheme 1). The eliminative crosscoupling of carbenoids can provide a way to unsymmetrical alkenes, provided the differential reactivity of the two carbenoids is suitably matched [2]. In the current letter, we report preliminary results on the latter strategy to form alkenes which possess an allylic heteroatom (hydroxy, amino) functionality (Scheme 2).

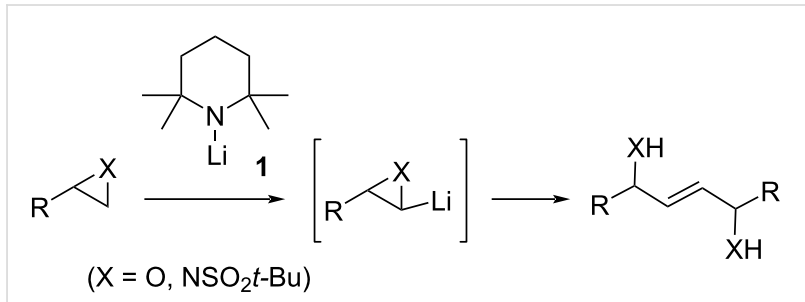

Scheme 1: Dimerisation of $\alpha$-lithio epoxides or aziridines [3-5].

\section{Results and Discussion}

Our studies began (Scheme 3) by reaction of BuLi (4 equiv) with a mixture of stannane 4 [6] (2 equiv) and tetramethylpiperidine (TMP, 2 equiv), to generate methoxymethyllithium and LTMP, followed by addition of terminal epoxide $\mathbf{5}$. This led to 


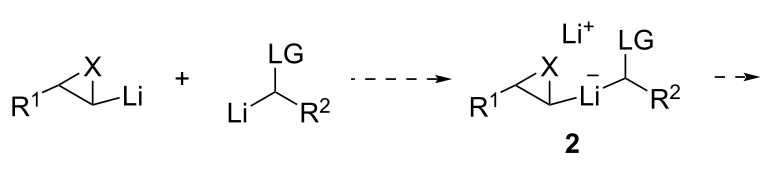<smiles>[R]C=CC([R])[M]</smiles>

(LG = leaving group, e.g. OMe)

Scheme 2: Proposed eliminative cross-coupling of carbenoids to allylic alcohols $(X=O)$ or allylic amines $\left(X=\mathrm{NSO}_{2} t-\mathrm{Bu}\right)$.

the desired allylic alcohol 6 (38\%), likely via the selective (ring strain-relieving) 1,2-metalate rearrangement outlined in Scheme $2(\mathbf{2} \rightarrow \mathbf{3}, \mathrm{X}=\mathrm{O}, \mathrm{LG}=\mathrm{OMe})$, then preferential $\beta$-elimination $[7,8]$ of lithium methoxide rather than dilithium oxide. However, also isolated was dodecanal (50\%), which arises from hydrolysis during work-up of the enamine that is formed from trapping of the lithiated epoxide by LTMP $[9,10]$. Omitting LTMP gave a significantly improved yield of the allylic alcohol 6 (79\%, using BuLi and stannane 4 (3 equiv each)). This latter result suggests that methoxymethyllithium is capable of deprotonating terminal epoxide $\mathbf{5}$, and this occurs in preference to direct attack at the (unlithiated) epoxide 5. In contrast, no reaction was observed with a 2,2-disubstituted epoxide: 1-oxaspiro[2.11]tetradecane (9) [11] being recovered (90\%) under the reaction conditions.

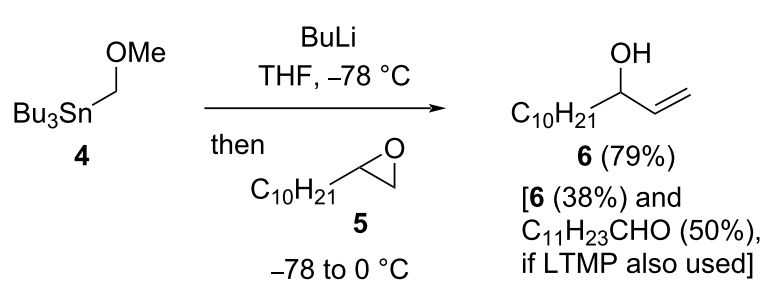

Scheme 3: Allylic alcohol 6 by one-carbon homologation from epoxide 5 .

The one-carbon homologation of an epoxide to an allylic alcohol (cf Scheme 3) can also be achieved using excess dimethylsulfonium methylide [12,13], although non-terminal alkenes have not been shown to be directly accessible by higher homologation. To examine the latter in the context of the current chemistry, $\alpha$-methoxyhexyllithium derived from stannane 7 $[14,15]$ was reacted with terminal epoxide $\mathbf{5}$, which gave the allylic alcohol 8 (79\%, E/Z = 73:27, Scheme 4). This organolithium also proved reactive with 2,2-disubstituted epoxide $\mathbf{9}$, giving allylic tertiary alcohol $\mathbf{1 0}(72 \%, E / Z=82: 18)$.

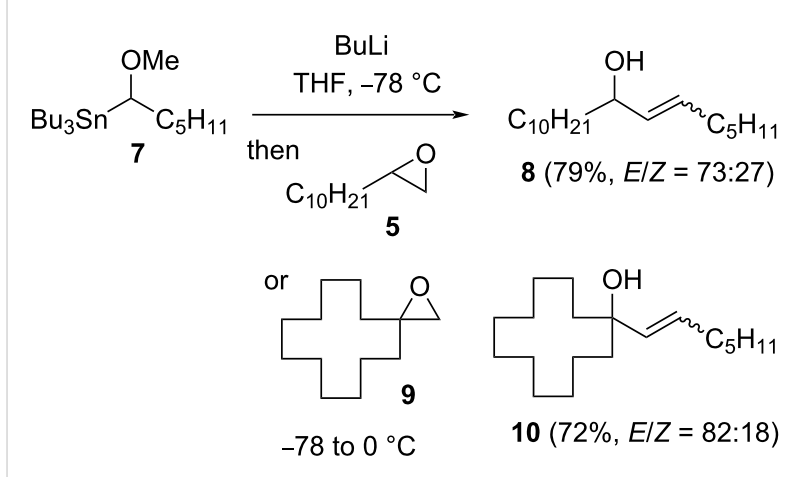

Scheme 4: Internal allylic alcohols from epoxides and stannane 7.

A trisubstituted alkene 12 (30\%) could be formed from terminal epoxide 5, using cyclopropylstannane 11 [16] (Scheme 5); in this case the presence of LTMP was also necessary as epoxide $\mathbf{5}$ was recovered $(>80 \%)$ in its absence.

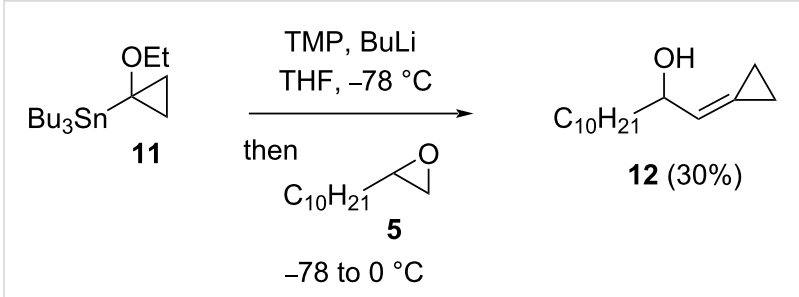

Scheme 5: Cyclopropylidene synthesis from epoxide $\mathbf{5}$.

A silyl-stabilised methoxymethyllithium, available by direct lithiation of (methoxymethyl)trimethylsilane (13) [17], gave vinylsilane $14(26 \%, E / Z=81: 19)$ on reaction with terminal epoxide 5 in the presence of LTMP (Scheme 6); the allylic

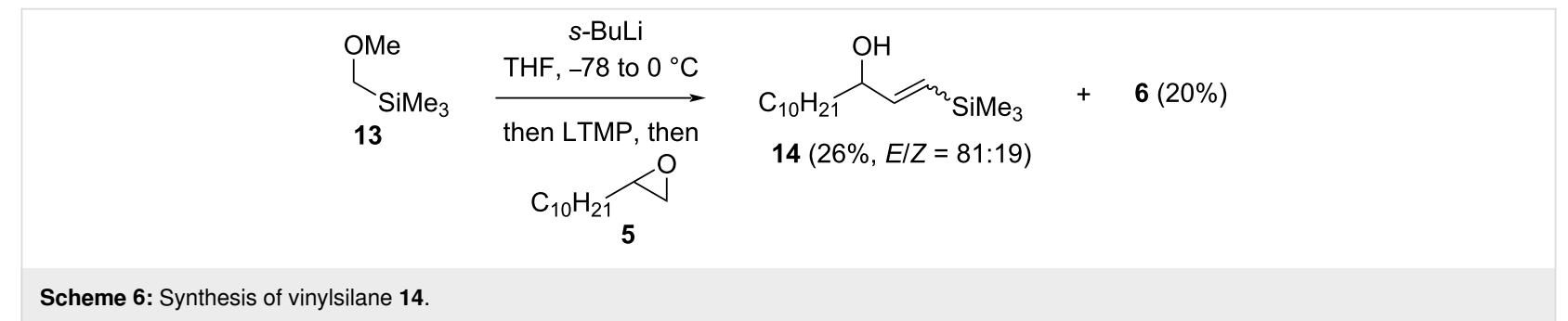


alcohol 6 was also isolated (20\%), suggesting that in our hands lithium-trimethylsilyl exchange competes with lithiation of (methoxymethyl)trimethylsilane (13).

Access to allylic alcohol 8 was also achievable (55\%, $E / Z=56: 44)$ in a tin-free process using a sulfonyl leaving group, via $\alpha$-lithiation of sulfone 15 [18] and in the presence of LTMP (Scheme 7). $\gamma$-Hydroxysulfone $\mathbf{1 6}$ was formed competitively $(44 \%, \mathrm{dr}=50: 50)$, by direct addition of the lithiated sulfone to (unlithiated) epoxide $\mathbf{5}$ and was formed quantitatively $(\mathrm{dr}=57: 43)$ if the LTMP was omitted.

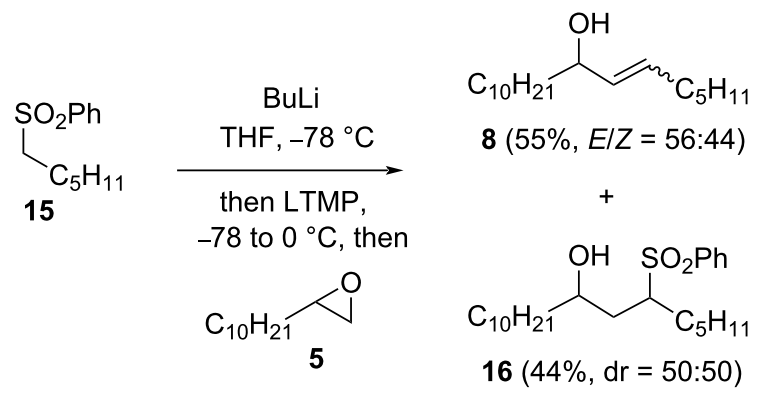

Scheme 7: Allylic alcohol 8 from epoxide 5 and sulfone 15.

Analogous chemistry to that described above (Scheme 3 and Scheme 4) was found to be possible with a terminal aziridine 17, providing access to the corresponding $N$-Bus-protected allylic amines 18 [19] and 19 (Scheme 8). In these cases, the amines are formed by preferential $\beta$-elimination $[20,21]$ of lithium methoxide rather than $\mathrm{BusNLi}_{2}$.

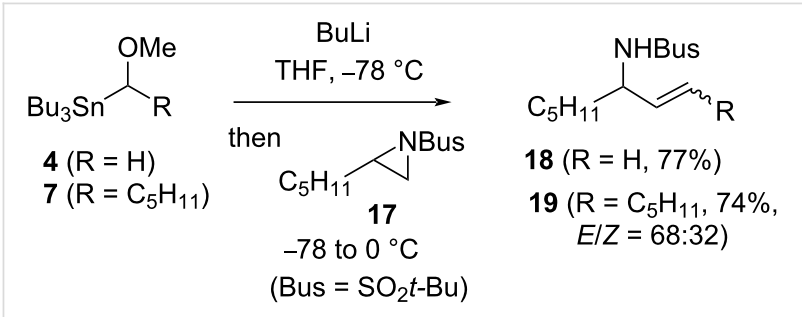

Scheme 8: Allylic amines from aziridine 17.

Synthesis of cyclopropylidene 21 (Scheme 9), suggests a terminal $N$-Bus-aziridine is capable of being deprotonated by the $\alpha$-lithio cyclopropane from stannane 11; this contrasts with cross-coupling using the same carbenoid and epoxide $\mathbf{5}$ (Scheme 5), where the presence of LTMP also proved necessary.

A cinnamylamine $\mathbf{2 3}$ could be obtained in a tin-free process (Scheme 10), which utilises the increased acidity of a benzylic

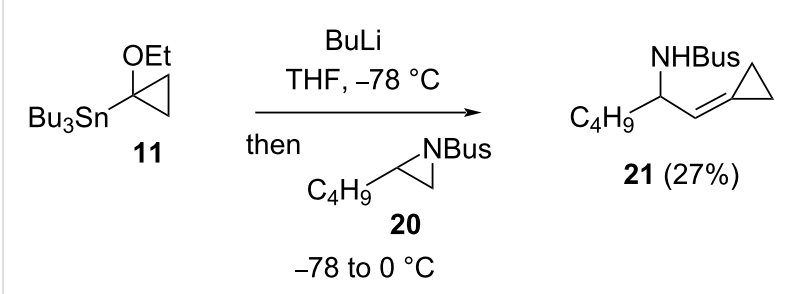

Scheme 9: Cyclopropylidene synthesis from aziridine 20.

ether 22. In this case, the presence of LTMP was necessary as only $\gamma$-amino ether $\mathbf{2 5}$ was observed in its absence. It was also important to carry out the reaction at $-78{ }^{\circ} \mathrm{C}$ to avoid a 1,2 Wittig rearrangement of the lithiated benzyl ether [22]; this restricts the reaction to $N$-Bus-aziridines, as epoxides are not deprotonated by LTMP at such low temperatures. Alongside the cinnamylamine $\mathbf{2 3}$, small amounts of the aziridine-derived carbenoid dimerisation product, 2-ene-1,4-diamine 24 [5], were observed. While the reaction profile was not altered on a solvent switch to hexane $(\mathbf{2 3}(62 \%, E / Z=61: 39) ; 24(16 \%))$, the yield of cinnamylamine $\mathbf{2 3}$ was slightly improved in hexane $(69 \%, E / Z=62: 38)$ and the amount of dimer 24 curtailed $(8 \%)$ by reducing the amount of LTMP from 2 to 1.2 equiv.

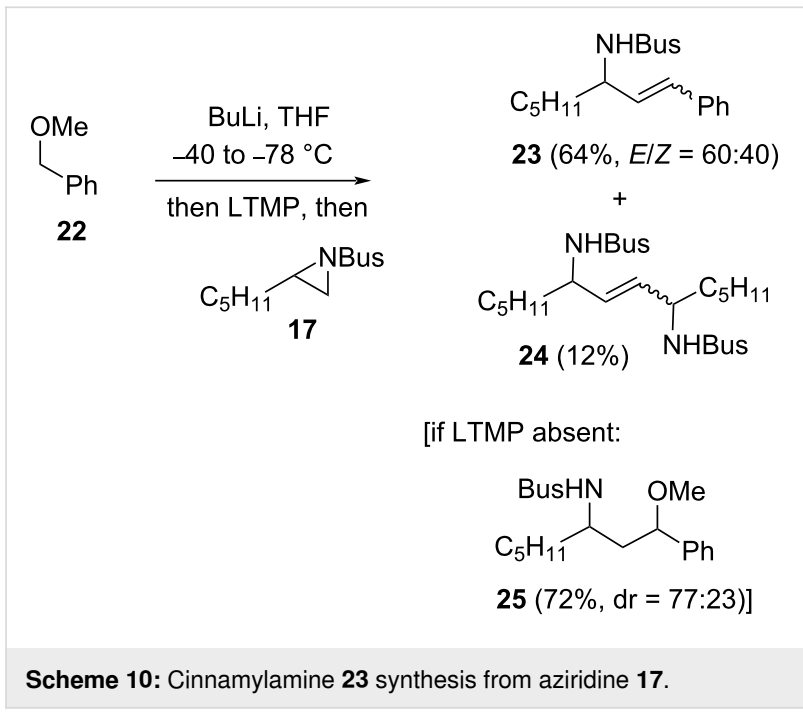

The viability of a benzyl ether (Scheme 10) in the carbenoid eliminative cross-coupling offered a straightforward way to probe any effect of the size of the leaving group on stereoselectivity. However, neither isopropyl or neopentyl benzylic ethers 26 and $27[23,24]$ led to a significant change in the $E / Z$ ratio for cinnamylamine 23 (Scheme 11).

\section{Conclusion}

In summary, we report a new, convergent access to allylic alcohols and amines. The process proceeds by selective cross-cou- 


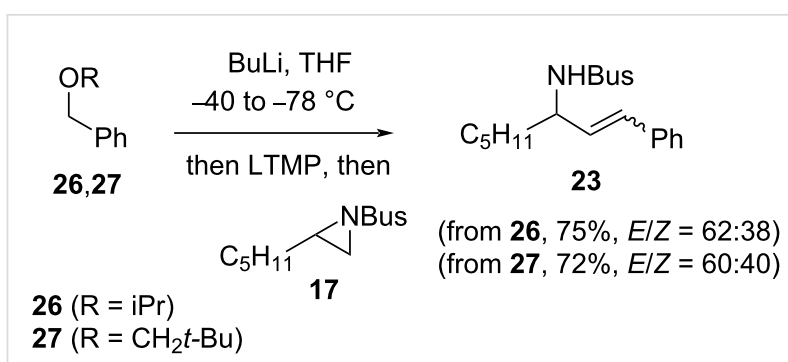

Scheme 11: Cinnamylamine 23 synthesis from isopropyl or neopentyl benzylic ethers 26 and 27

pling of $\alpha$-lithio terminal epoxides or $N$-Bus-aziridines with $\alpha$-lithio ethers. Where 1,2-disubstituted alkenes are generated the $E / Z$ stereoselectivity is modest, and preliminary results suggest the size of the leaving group does not play a significant role. However, the geometry of alkene formation might be controllable by using enantiomerically pure coupling partners [2]. Such terminal epoxides and aziridines are readily available $[3,5]$, while the corresponding $\alpha$-lithio ethers can be accessed from enantioenriched $\alpha$-stannyl ethers [25]. The enantiopure variants await future investigation.

\section{Supporting Information}

\section{Supporting Information File 1}

Experimental procedures and characterisation data for all new compounds.

[https://www.beilstein-journals.org/bjoc/content/ supplementary/1860-5397-17-155-S1.pdf]

\section{Acknowledgements}

We thank the EPSRC National Mass Spectrometry Service Centre for mass spectra.

\section{Funding}

The EPSRC and GlaxoSmithKline are acknowledged for a CASE studentship to M. J. F.

\section{ORCID ${ }^{\circledR}$ iDs}

David M. Hodgson - https://orcid.org/0000-0001-7201-9841

\section{References}

1. Williams, J. M. J., Ed. Preparation of Alkenes, A Practical Approach; Oxford University Press: Oxford, UK, 1996.

2. Blakemore, P. R.; Hoffmann, R. W. Angew. Chem., Int. Ed. 2018, 57, 390-407. doi:10.1002/anie.201707026

3. Hodgson, D. M.; Bray, C. D.; Kindon, N. D. Org. Lett. 2005, 7, 2305-2308. doi:10.1021/ol050402h
4. Hodgson, D. M.; Miles, S. M. Angew. Chem., Int. Ed. 2006, 45, 935-938. doi:10.1002/anie.200503303

5. Hodgson, D. M.; Humphreys, P. G.; Miles, S. M.; Brierley, C. A. J.; Ward, J. G. J. Org. Chem. 2007, 72, 10009-10021. doi:10.1021/jo701901t

6. Kaufman, T. S. Synlett 1997, 1377-1378. doi:10.1055/s-1997-1064

7. Dechoux, L.; Doris, E.; Mioskowski, C. Chem. Commun. 1996, 549-550. doi:10.1039/cc9960000549

8. Hodgson, D. M.; Stent, M. A. H.; Wilson, F. X. Synthesis 2002, 1445-1453. doi:10.1055/s-2002-33112

9. Hodgson, D. M.; Bray, C. D.; Kindon, N. D. J. Am. Chem. Soc. 2004 , 126, 6870-6871. doi:10.1021/ja031770o

10. Hodgson, D. M.; Bray, C. D.; Kindon, N. D.; Reynolds, N. J.; Coote, S. J.; Um, J. M.; Houk, K. N. J. Org. Chem. 2009, 74, 1019-1028. doi:10.1021/jo802016t

11. Michnick, T. J.; Matteson, D. S. Synlett 1991, 631-632. doi:10.1055/s-1991-20821

12. Alcaraz, L.; Harnett, J. J.; Mioskowski, C.; Martel, J. P.; Le Gall, T.; Shin, D.-S.; Falck, J. R. Tetrahedron Lett. 1994, 35, 5449-5452. doi:10.1016/s0040-4039(00)73522-2

13. Alcaraz, L.; Cridland, A.; Kinchin, E. Org. Lett. 2001, 3, 4051-4053. doi:10.1021/ol016782y

14. Still, W. C. J. Am. Chem. Soc. 1978, 100, 1481-1487. doi:10.1021/ja00473a025

15. Linderman, R. J.; Siedlecki, J. M. J. Org. Chem. 1996, 61, 6492-6493. doi:10.1021/jo961161h

16. Gadwood, R. C.; Rubino, M. R.; Nagarajan, S. C.; Michel, S. T. J. Org. Chem. 1985, 50, 3255-3260. doi:10.1021/jo00218a003

17. Magnus, P.; Roy, G. Organometallics 1982, 1, 553-559. doi:10.1021/om00063a027

18. Orita, A.; Yoshioka, N.; Struwe, P.; Braier, A.; Beckmann, A.; Otera, J. Chem. - Eur. J. 1999, 5, 1355-1363. doi:10.1002/(sici)1521-3765(19990401)5:4<1355::aid-chem1355>3.0.c $0 ; 2-0$

19. Hodgson, D. M.; Fleming, M. J.; Stanway, S. J. Org. Lett. 2005, 7, 3295-3298. doi:10.1021/ol051124p

20. Hodgson, D. M.; Štefane, B.; Miles, T. J.; Witherington, J. Chem. Commun. 2004, 2234-2235. doi:10.1039/b409486g

21. Hodgson, D. M.; Štefane, B.; Miles, T. J.; Witherington, J. J. Org. Chem. 2006, 71, 8510-8515. doi:10.1021/jo0615201

22. Azzena, U.; Pilo, L.; Sechi, A. Tetrahedron 1998, 54, 12389-12398. doi:10.1016/s0040-4020(98)00758-3

23. Kim, J. D.; Han, G.; Jeong, L. S.; Park, H.-J.; Zee, O. P.; Jung, Y. H. Tetrahedron 2002, 58, 4395-4402. doi:10.1016/s0040-4020(02)00413-1

24. Caubere, P.; Moreau, J. Tetrahedron 1970, 26, 2637-2647. doi:10.1016/s0040-4020(01)92838-8

25. Clayden, J. Organolithiums: Selectivity for Synthesis; Pergamon Press: Oxford, UK, 2002; pp 178-180. 


\section{License and Terms}

This is an Open Access article under the terms of the Creative Commons Attribution License (https://creativecommons.org/licenses/by/4.0). Please note that the reuse, redistribution and reproduction in particular requires that the author(s) and source are credited and that individual graphics may be subject to special legal provisions.

The license is subject to the Beilstein Journal of Organic Chemistry terms and conditions:

(https://www.beilstein-journals.org/bjoc/terms)

The definitive version of this article is the electronic one which can be found at:

$\underline{\text { https://doi.org/10.3762/bjoc.17.155 }}$ 